\title{
Use of $\mathrm{CHA}_{2} \mathrm{DS}_{2}-\mathrm{VASc}$ Score to Predict New-Onset Atrial Fibrillation in Chronic Obstructive Pulmonary Disease Patients
}

\author{
- Large-Scale Longitudinal Study -
}

\author{
Wei-Syun Hu, MD, PhD; Cheng-Li Lin, BSc
}

Background: The aim of this study was to assess the accuracy of $\mathrm{CHA}_{2} \mathrm{DS}_{2}$-VASc score in predicting new-onset atrial fibrillation $(A F)$ in patients with chronic obstructive pulmonary disease (COPD).

Methods and Results: A total of 50,430 COPD patients were enrolled in this study. The area under the receiver operating characteristic curve (AUC) and the Cox model c-statistic were used to assess the association between new-onset $A F$ risk and $\mathrm{CHA}_{2} \mathrm{DS} \mathrm{S}_{2}-$ VASc score in COPD patients. After adjustment for comorbidities other than the components of $\mathrm{CHA}_{2} \mathrm{DS}_{2}-\mathrm{VASc}_{\mathrm{Score}}$, risk of new-onset $\mathrm{AF}$ in COPD patients increased from 1.24 (95\% confidence interval (Cl): 1.01-1.52) for a score of 1 , to 2.15 (95\% $\mathrm{Cl}$ : 1.62-2.86) for score $\geq 6$ (trend test, $\mathrm{P}<0.001$ ), compared with $\mathrm{CHA}_{2} \mathrm{DS}_{2}-\mathrm{VASc}$ score 0 . The AUC for $\mathrm{CHA}_{2} \mathrm{DS} \mathrm{S}_{2}-\mathrm{VASc}$ score in predicting new-onset AF in COPD patients was 0.69 (95\% Cl: 0.68-0.70). The c-statistic of Cox model in predicting incident AF was 0.73.

Conclusions: Risk of new-onset AF in COPD patients increased with increasing $\mathrm{CHA}_{2} \mathrm{DS}_{2}-\mathrm{VASc}$ score. The predictive ability of the score was moderate. $\mathrm{CHA}_{2} \mathrm{DS}_{2}-\mathrm{VASc}$ score might be used as a screening tool for AF in COPD patients.

Key Words: Atrial fibrillation; $\mathrm{CHA}_{2} \mathrm{DS}_{2}$-VASc score; Chronic obstructive pulmonary disease

$\mathrm{C}$ hronic obstructive pulmonary disease (COPD), one of the leading causes of death in the world, is associated with cardiovascular disease (CVD). ${ }^{1-4}$ Atrial fibrillation (AF) is a common arrhythmia and is associated with several cardiovascular morbidities. ${ }^{58}$ The connection between COPD and AF has been proposed; indeed, the negative prognostic impact of AF on patients with COPD has also been reported.9-14

$\mathrm{CHA}_{2} \mathrm{DS}_{2}-\mathrm{VASc}$ score, the clustering of several CVDrelated risk factors, was initially proposed for stroke prediction in non-valvular AF. ${ }^{15-17}$ Recently, the role of $\mathrm{CHA}_{2} \mathrm{DS}_{2}$-VASc score has been expanded to predict different adverse cardiac and cerebrovascular outcomes in different populations. ${ }^{18-21}$ In order to reduce AF-related adverse cardiovascular events in COPD patients, it is essential to construct an accurate, convenient and easy-to-use risk stratification model for prediction of new-onset $\mathrm{AF}$ in COPD patients. Using a nationwide cohort, this study assessed the accuracy of $\mathrm{CHA}_{2} \mathrm{DS}_{2}-\mathrm{VASc}$ score in predicting incident $\mathrm{AF}$ in this population.

\section{Editorial p1766}

Methods
Data Source
Since 1995, Taiwan's National Health Insurance (NHI)
Bureau has provided a single-payer health insurance pro-
gram with a coverage rate of $>99 \%$ of residents in Taiwan.
The Longitudinal Health Insurance Database 2000 (LHID
2000) of the NHI program was obtained. Detailed descrip-
tions of the LHID 2000 have been reported previously.
The diagnosis of the disease was coded based on the Inter-
national Classification of Diseases, Ninth Revision, Clinical
Modification (ICD-9-CM). This study was approved by
the Institutional Review Board (IRB) of China Medical
University and Hospital (CMUH104-REC2-115).

Sampled Participants

The subject selection procedure is shown in Figure 1. Between 1 January 2000 and 31 December 2011, the date of diagnosis of COPD (ICD-9-CM codes 491, 492, 496)

Received February 7, 2017; revised manuscript received May 5, 2017; accepted May 13, 2017; released online June 16, 2017 Time for primary review: 49 days

School of Medicine, College of Medicine, China Medical University, Taichung (W.-S.H.); Division of Cardiovascular Medicine, Department of Medicine (W.-S.H.), Management Office for Health Data (C.-L.L.), China Medical University Hospital, Taichung, Taiwan

Mailing address: Wei-Syun $\mathrm{Hu}, \mathrm{MD}$, PhD, Division of Cardiovascular Medicine, Department of Medicine, China Medical University Hospital, 2, Yuh-Der Road, Taichung 40447, Taiwan. E-mail: weisyunhu@gmail.com

ISSN-1346-9843 All rights are reserved to the Japanese Circulation Society. For permissions, please e-mail: cj@j-circ.or.jp 
was defined as the index date. Patients aged $\geq 18$ years at the index date were included in the present study. We excluded patients who had a diagnosis of AF or atrial flutter (ICD-9-CM code 427.31, 427.32) before the index date. $\mathrm{CHA}_{2} \mathrm{DS}_{2}-\mathrm{VASc}$ score was used to estimate the risk of incident $\mathrm{AF}$ in patients with COPD. ${ }^{25,26}$ Comorbidities associated with AF development, such as cancer (ICD9-CM codes 140-208), hyperlipidemia (ICD-9-CM code 272), chronic kidney disease (ICD-9-CM code 585), hyperthyroidism (ICD-9-CM code 242) and valvular heart disease (ICD-9-CM code 424) were noted. All subjects were followed up until occurrence of new-onset AF, censoring because of death, withdrawal from the NHI program, or at the end of 2011 (whichever occurred first).

\section{Statistical Analysis}

Demographic data are presented as mean \pm SD for continuous variables and as number and percentage for categorical variables. The categorical variables and the continuous variables were compared using chi-squared test

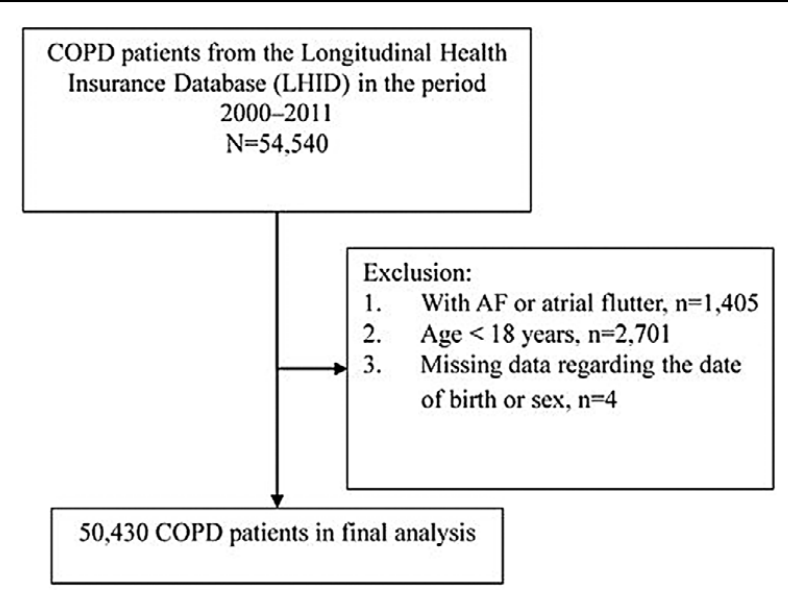

Figure 1. Subject selection. AF, atrial fibrillation; COPD, chronic obstructive pulmonary disease.

\begin{tabular}{|c|c|c|c|}
\hline \multirow{2}{*}{ Variable } & \multicolumn{2}{|c|}{ AF } & \multirow{2}{*}{ P-value } \\
\hline & No $(n=47,980)$ & Yes $(n=2,450)$ & \\
\hline Age (years) & & & $<0.001^{\dagger}$ \\
\hline$\leq 64$ & $28,378(59.2)$ & $581(23.7)$ & \\
\hline $65-74$ & $11,218(23.4)$ & $891(36.4)$ & \\
\hline$\geq 75$ & $8,384(17.5)$ & $978(39.9)$ & \\
\hline Mean \pm SD & $59.1 \pm 16.3$ & $71.6 \pm 10.7$ & $<0.001^{\ddagger}$ \\
\hline Sex & & & $<0.001^{\dagger}$ \\
\hline Male & $27,298(56.9)$ & $1,489(60.8)$ & \\
\hline Female & $20,682(43.1)$ & $861(39.2)$ & \\
\hline \multicolumn{4}{|c|}{ Underlying disease (components of $\mathrm{CHA}_{2} \mathrm{DS}_{2}$-VASc score) } \\
\hline $\mathrm{CHF}$ & $2,238(4.66)$ & $406(16.6)$ & $<0.001^{\dagger}$ \\
\hline Diabetes mellitus & $5,825(12.1)$ & $328(13.4)$ & $0.07^{\dagger}$ \\
\hline CVA or TIA & $3,127(6.52)$ & 235 (9.59) & $<0.001^{\dagger}$ \\
\hline Vascular disease & $2,347(4.89)$ & $175(7.14)$ & $<0.001^{\dagger}$ \\
\hline Hypertension & $22,792(47.5)$ & $1,795(73.3)$ & $<0.001^{\dagger}$ \\
\hline \multicolumn{4}{|l|}{ Other underlying disease } \\
\hline Cancer & $1,676(3.49)$ & 83 (3.39) & $0.78^{\dagger}$ \\
\hline Hyperlipidemia & $12,203(25.4)$ & $665(27.1)$ & $0.06^{\dagger}$ \\
\hline CKD & $5,411(11.3)$ & $413(16.9)$ & $<0.001^{\dagger}$ \\
\hline Hyperthyroidism & $1,449(3.02)$ & $62(2.53)$ & $0.17^{\dagger}$ \\
\hline Valvular heart disease & $1,171(2.44)$ & $131(5.35)$ & $<0.001^{\dagger}$ \\
\hline $\mathrm{CHA}_{2} \mathrm{DS}_{2}$-VASc score & & & $<0.001^{\dagger}$ \\
\hline 0 & $9,636(20.1)$ & $124(5.06)$ & \\
\hline 1 & $1,4661(30.6)$ & $354(14.5)$ & \\
\hline 2 & $9,731(20.3)$ & $583(23.8)$ & \\
\hline 3 & $6,781(14.1)$ & $625(25.5)$ & \\
\hline 4 & $3,998(8.33)$ & $419(17.1)$ & \\
\hline 5 & $1,866(3.89)$ & $213(8.69)$ & \\
\hline 6 & $903(1.88)$ & $87(3.55)$ & \\
\hline 7 & $322(0.67)$ & $38(1.55)$ & \\
\hline 8 & $74(0.15)$ & $5(0.20)$ & \\
\hline 9 & $8(0.02)$ & $2(0.08)$ & \\
\hline $\mathrm{CHA}_{2} \mathrm{DS}_{2}$-VASc score & $1.84 \pm 1.56$ & $2.85 \pm 1.55$ & $<0.001^{\ddagger}$ \\
\hline Follow-up (years) & $6.91 \pm 3.51$ & $4.08 \pm 3.00$ & $<0.001^{\ddagger}$ \\
\hline
\end{tabular}

Data given as $\mathrm{n}(\%)$ or mean $\pm \mathrm{SD}$. ${ }^{+}$Chi-squared test; tt-test. $\mathrm{AF}$, atrial fibrillation; $\mathrm{CHF}$, congestive heart failure; CKD, chronic kidney disease; COPD, chronic obstructive pulmonary disease; CVA, cerebrovascular accident; TIA, transient ischemic attack. 


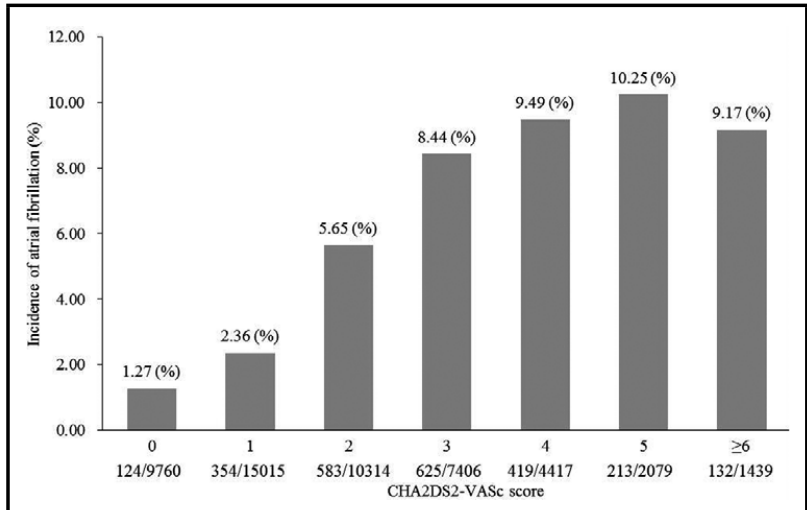

Figure 2. Incidence of new-onset atrial fibrillation (AF) increased with increasing $\mathrm{CHA}_{2} \mathrm{DS}_{2}-\mathrm{VASc}$ score in chronic obstructive pulmonary disease patients. and Student's t-test, respectively. The incidence density rate (1,000 person-years) of new-onset AF was estimated according to $\mathrm{CHA}_{2} \mathrm{DS}_{2}-\mathrm{VASc}$ score. Univariable and multivariable Cox proportional hazard regression models were used to assess the risk of new-onset AF in patients with COPD according to $\mathrm{CHA}_{2} \mathrm{DS}_{2}-\mathrm{VASc}$ score. The Cox models were also used to examine the effect of factors of $\mathrm{CHA}_{2} \mathrm{DS}_{2}-$ VASc score on the risk of incident AF in COPD patients. $\mathrm{CHA}_{2} \mathrm{DS}_{2}-\mathrm{VASc}$ score-specific survival probability for AF was analyzed using Kaplan-Meier survival for actual incidence and Cox modeling for estimated incidence, respectively. Area under the receiver operating characteristic (ROC) curve (AUC) was used to quantify the discriminatory performance of $\mathrm{CHA}_{2} \mathrm{DS}_{2}-\mathrm{VASc}$ score in predicting new-onset AF in COPD patients. Moreover, the c-statistic was also estimated based upon Cox regression analysis. ${ }^{27}$ All statistical analyses were performed using SAS 9.4 (SAS Institute, Cary, NC, USA). The significance level for all analyses was set at $\mathrm{P}<0.05$.

\begin{tabular}{|c|c|c|c|c|c|c|c|c|}
\hline $\begin{array}{c}\text { Variables } \\
\mathrm{CHA}_{2} \mathrm{DS}_{2} \text {-VASc } \mathrm{s}\end{array}$ & $\mathbf{n}$ & $\begin{array}{l}\text { No. } \\
\text { events }\end{array}$ & $\begin{array}{l}\text { Person- } \\
\text { years }\end{array}$ & $\begin{array}{l}\text { Rate per } 1,000 \\
\text { person-years }\end{array}$ & $\begin{array}{l}\text { Age- and sex- } \\
\text { adjusted HR }\end{array}$ & $95 \% \mathrm{Cl}$ & $\begin{array}{c}\text { Adjusted } \\
\mathrm{HR}^{\dagger}\end{array}$ & $95 \% \mathrm{Cl}$ \\
\hline 0 & 9,760 & 124 & 73,153 & 1.70 & 1 & (Ref.) & 1 & (Ref.) \\
\hline 1 & 15,015 & 354 & 111,981 & 3.16 & 1.45 & $(1.17-1.79)^{\star * *}$ & 1.24 & $(1.01-1.52)^{\star}$ \\
\hline 2 & 10,314 & 583 & 71,701 & 8.13 & 1.89 & $(1.52-2.35)^{\star \star \star}$ & 1.56 & $(1.26-1.93)^{\star \star \star}$ \\
\hline 3 & 7,406 & 625 & 46,050 & 13.6 & 2.26 & $(1.79-2.85)^{\star \star \star}$ & 1.72 & $(1.38-2.15)^{\star \star \star}$ \\
\hline 4 & 4,417 & 419 & 23,971 & 17.5 & 2.60 & $(2.02-3.35)^{\star \star \star}$ & 1.80 & $(1.42-2.28)^{\star \star \star}$ \\
\hline 5 & 2,079 & 213 & 9,406 & 22.7 & 3.14 & $(2.39-4.12)^{\star * *}$ & 2.14 & $(1.73-2.90)^{\star \star \star}$ \\
\hline$\geq 6$ & 1,439 & 132 & 5,103 & 25.9 & 3.28 & $(2.43-4.43)^{\star \star \star}$ & 2.15 & $(1.62-2.86)^{\star \star \star}$ \\
\hline$P$ for trend & & & & & $<0.001$ & & $<0.001$ & \\
\hline
\end{tabular}

${ }^{*} \mathrm{P}<0.05,{ }^{* \star} \mathrm{P}<0.01,{ }^{* \star *} \mathrm{P}<0.001 .{ }^{\dagger}$ Adjusted for cancer, hyperlipidemia, $\mathrm{CKD}$, hyperthyroidism and valvular heart disease. Abbreviations as in Table 1.

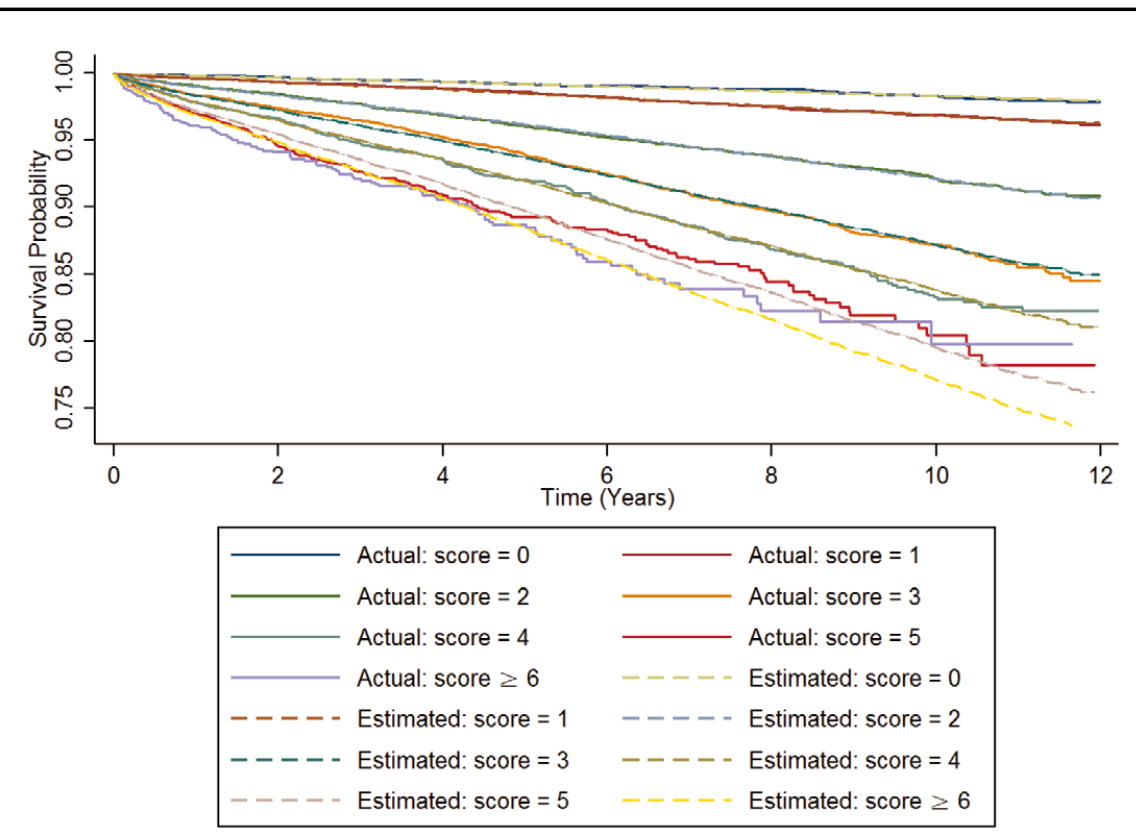

Figure 3. Actual vs. estimated survival curves for new-onset atrial fibrillation stratified by $\mathrm{CHA}_{2} \mathrm{DS}_{2}-$ VASc score in patients with chronic obstructive pulmonary disease. 


\section{Results}

Eligible study participants consisted of 50,430 COPD patients; among them, 2,450 patients developed new-onset AF whereas 47,980 patients did not (Table 1). Mean age was $71.6 \pm 10.7$ years for the AF group and 59.1 \pm 16.3 years for the non-AF group. Hypertension was the most common comorbid illness $(73.3 \%$ vs. $47.5 \%)$ in both groups. Mean $\mathrm{CHA}_{2} \mathrm{DS}_{2}-\mathrm{VASc}$ score was $2.85 \pm 1.55$ for the AF group and $1.84 \pm 1.56$ for the non-AF group. Mean follow-up period was $4.08 \pm 3.00$ years for the AF group and $6.91 \pm 3.51$ years for the non-AF group.

The incidence of new-onset AF increased from $1.27 \%$ in COPD patients with $\mathrm{CHA}_{2} \mathrm{DS}_{2}-\mathrm{VASc}$ score 0 to $9.17 \%$ in COPD patients with $\mathrm{CHA}_{2} \mathrm{DS}_{2}$-VASc score $\geq 6$ (Figure 2). After adjusting for age and sex, as compared with COPD patients with $\mathrm{CHA}_{2} \mathrm{DS}_{2}-\mathrm{VASc}$ score 0 , the corresponding adjusted hazard ratios (aHR) for new-onset AF increased with increasing $\mathrm{CHA}_{2} \mathrm{DS}_{2}-\mathrm{VASc}$ score. Furthermore, after adjusting for cancer, hyperlipidemia, chronic kidney disease, hyperthyroidism and valvular heart disease, as compared with COPD patients with $\mathrm{CHA}_{2} \mathrm{DS}_{2}$-VASc score 0 , the corresponding aHR for new-onset $\mathrm{AF}$ for $\mathrm{CHA}_{2} \mathrm{DS}_{2}-\mathrm{VASc}$ score $1,2,3,4,5$ and $\geq 6$, were 1.24 (95\% confidence interval (CI): 1.01-1.52), 1.56 (95\% CI: 1.26-1.93), 1.72 (95\% CI: 1.38-2.15), 1.80 (95\% CI: 1.42-2.28), 2.14 (95\% CI: $1.73-$ $2.90)$ and 2.15 (95\% CI: 1.62-2.86), respectively (trend test, $\mathrm{P}<0.001$; Table 2).

Figure 3 shows the 12-year survival probability curves for AF stratified by $\mathrm{CHA}_{2} \mathrm{DS}_{2}-\mathrm{VASc}$ score. There was a close approximation between the estimated and actual curves, suggesting that the $\mathrm{CHA}_{2} \mathrm{DS}_{2}$-VASc score did not overfit the data in this cohort.

The AUC for $\mathrm{CHA}_{2} \mathrm{DS}_{2}-\mathrm{VASc}$ score in predicting newonset AF in patients with COPD was 0.69 (95\% CI: 0.68 0.70; Figure 4). The Harrell C-statistic for incident AF was 0.73 based on Cox-regression analysis. The results of the univariable and multivariable Cox proportional hazards regression models for analyzing the risk of new-onset AF contributed by the factors of $\mathrm{CHA}_{2} \mathrm{DS}_{2}-\mathrm{VASc}$ score are listed in Table 3. Compared with patients aged $\leq 64$ years, the risk of AF was 3.08-fold higher in those aged 65-74 years (95\% CI: 2.76-3.44), and 5.64-fold higher in those aged $\geq 75$ years $(95 \%$ CI: $5.04-6.30)$. The aHR of AF was 1.21 -fold higher in men than in women $(95 \% \mathrm{CI}$ : $1.12-$ 1.31). The risk of AF was greater in patients with comorbidities, namely congestive heart failure (aHR, 2.67, 95\% CI: $2.39-2.98)$ and hypertension (aHR, 1.76, 95\% CI: $1.59-1.94)$.

\section{Discussion}

To the best of our knowledge, the present study is the first to investigate the accuracy of $\mathrm{CHA}_{2} \mathrm{DS}_{2}$-VASc score in

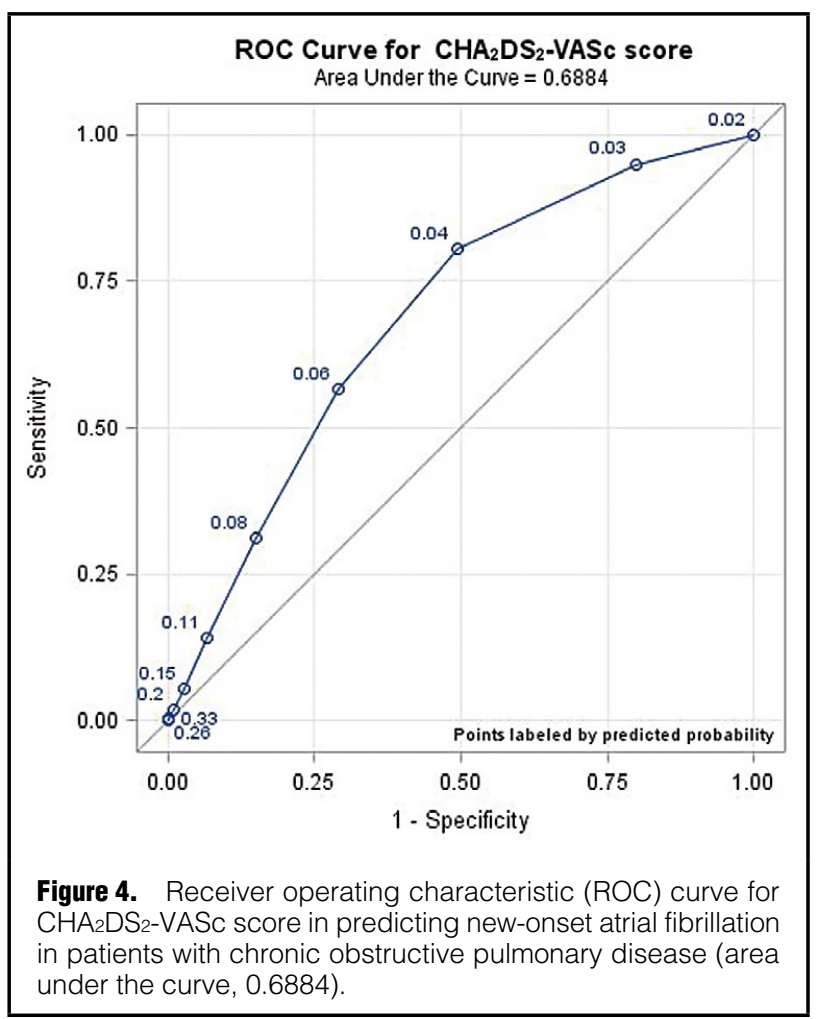

Table 3. $\mathrm{HR}$ and $95 \% \mathrm{Cl}$ for $\mathrm{AF}$ vs. $\mathrm{CHA}_{2} \mathrm{DS}_{2}-\mathrm{VASc}$ Score Components

\begin{tabular}{|c|c|c|c|c|}
\hline \multirow{2}{*}{ Variable } & \multicolumn{2}{|c|}{ Crude } & \multicolumn{2}{|c|}{ Adjusted ${ }^{\dagger}$} \\
\hline & HR & $(95 \% \mathrm{Cl})$ & HR & $(95 \% \mathrm{Cl})$ \\
\hline \multicolumn{5}{|l|}{ Age (years) } \\
\hline$\leq 64$ & 1.00 & (Ref.) & 1.00 & (Ref.) \\
\hline $65-74$ & 4.10 & $(3.69-4.55)^{\star \star \star}$ & 3.08 & $(2.76-3.44)^{\star * *}$ \\
\hline$\geq 75$ & 8.11 & $(7.31-8.99)^{\star \star \star}$ & 5.64 & $(5.04-6.30)^{\star \star \star}$ \\
\hline \multicolumn{5}{|l|}{ Sex } \\
\hline Male & 1.25 & $(1.15-1.35)^{\star \star \star}$ & 1.21 & $(1.12-1.31)^{\star * \star}$ \\
\hline Female & 1.00 & (Ref.) & 1.00 & (Ref.) \\
\hline \multicolumn{5}{|c|}{$\begin{array}{l}\text { Underlying disease (components of } \mathrm{CHA}_{2} \mathrm{DS}_{2-} \\
\text { VASc score) }\end{array}$} \\
\hline $\mathrm{CHF}$ & 4.89 & $(4.39-5.44)^{\star * *}$ & 2.67 & $(2.39-2.98)^{\star \star \star}$ \\
\hline Diabetes mellitus & 1.34 & $(1.19-1.50)^{\star \star \star}$ & 0.90 & $(0.80-1.01)$ \\
\hline CVA or TIA & 2.30 & $(2.01-2.63)^{\star \star \star}$ & 1.13 & $(0.98-1.30)$ \\
\hline Vascular disease & 1.92 & $(1.64-2.24)^{\star \star \star}$ & 1.09 & $(0.93-1.27)$ \\
\hline Hypertension & 3.27 & $(2.99-3.58)^{\star \star \star}$ & 1.76 & $(1.59-1.94)^{\star \star \star}$ \\
\hline
\end{tabular}

${ }^{* \star *} \mathrm{P}<0.001 .{ }^{\dagger}$ Adjusted for cancer, hyperlipidemia, chronic kidney disease, hyperthyroidism and valvular heart disease. Abbreviations as in Table 1. 
predicting new-onset AF in COPD patients. New-onset AF risk was found to be increased in parallel with increasing $\mathrm{CHA}_{2} \mathrm{DS}_{2}$-VASc score.

Coexistence of COPD and AF is common and the interplay between them is complex. COPD patients are at an increased risk of incident AF. ${ }^{28-30}$ Additionally, the adverse impact of incident AF on the clinical outcomes in COPD has also been proposed. ${ }^{\mathbf{1 2}-14}$ To our knowledge, however, there is no research specifically addressing the risk prediction model for incident AF in COPD. In order to fill the knowledge gaps, the present study investigated the role of $\mathrm{CHA}_{2} \mathrm{DS}_{2}$-VASc score in predicting incidence of $\mathrm{AF}$, using a large-scale cohort of 50,430 COPD patients and a mean follow-up period of 6.77 years. $\mathrm{CHA}_{2} \mathrm{DS}_{2}$-VASc score was found to be predictive of incident AF in COPD patients. More studies are needed to clarify the present findings.

Although several risk stratification models for AF development have been proposed, ${ }^{31,32}$ to the best of our knowledge, research on $\mathrm{AF}$ prediction modeling for patients with COPD is currently unavailable. In the present study, risk of new-onset $\mathrm{AF}$ was increased in COPD patients with $\mathrm{CHA}_{2} \mathrm{DS}_{2}-\mathrm{VASc}$ score $\geq 1$, compared with $\mathrm{CHA}_{2} \mathrm{DS}_{2}$-VASc score 0 . Unlike other complicated risk stratification models for $\mathrm{AF}$ prediction, the advantages of using $\mathrm{CHA}_{2} \mathrm{DS}_{2}-\mathrm{VASc}$ score in predicting incident $\mathrm{AF}$ are its convenience, comprehensiveness and accuracy. ${ }^{31,32} \mathrm{CHA}_{2} \mathrm{DS}_{2}$-VASc score was also found to have moderate discriminative performance. Thus, $\mathrm{CHA}_{2} \mathrm{DS}_{2}-\mathrm{VASc}$ score is potentially useful in clinical settings.

\section{Study Limitations}

First, underestimation of AF incidence in this nationwide dataset is possible because AF cannot be identified if the patients do not seek medical advice. Second, personal healthassociated behaviors were not provided by this nationwide database. Third, the severity of COPD and the types of AF were not available. Finally, we were unable to compare the predictive performance of the previously reported AF risk scores $^{31,32}$ with the established $\mathrm{CHA}_{2} \mathrm{DS}_{2}-\mathrm{VASc}$ score due to the limitations of this nationwide database.

\section{Conclusions}

The current study is the first to evaluate the accuracy of $\mathrm{CHA}_{2} \mathrm{DS}_{2}-\mathrm{VASc}$ score in predicting incident $\mathrm{AF}$ in patients with COPD. The discriminatory capacity of the score was moderate. Therefore, $\mathrm{CHA}_{2} \mathrm{DS}_{2}$-VASc score might provide an easy way to stratify risk of new-onset $\mathrm{AF}$ in COPD patients.

\section{Acknowledgments}

This study was supported in part by Taiwan Ministry of Health and Welfare Clinical Trial and Research Center of Excellence (MOHW105-TDU-B-212-133019), China Medical University Hospital, Academia Sinica Taiwan Biobank Stroke Biosignature Project (BM10501010037), NRPB Stroke Clinical Trial Consortium (MOST 104-2325-B-039 -005), Tseng-Lien Lin Foundation, Taichung, Taiwan, Taiwan Brain Disease Foundation, Taipei, Taiwan, and Katsuzo and Kiyo Aoshima Memorial Funds, Japan.

\section{Disclosures}

The authors declare no conflict of interest.

\section{References}

1. Bhatt SP, Wells JM, Dransfield MT. Cardiovascular disease in COPD: A call for action. Lancet Respir Med 2014; 2: 783-785.
2. Müllerova H, Agusti A, Erqou S, Mapel DW. Cardiovascular comorbidity in COPD: Systematic literature review. Chest 2013; 144: $1163-1178$.

3. Bhatt SP, Dransfield MT. Chronic obstructive pulmonary disease and cardiovascular disease. Transl Res 2013; 162: 237-251.

4. Sin DD, Man SF. Chronic obstructive pulmonary disease: A novel risk factor for cardiovascular disease. Can J Physiol Pharmacol 2005; 83: 8-13.

5. January CT, Wann LS, Alpert JS, Calkins H, Cigarroa JE, Cleveland JC Jr, et al; American College of Cardiology/American Heart Association Task Force on Practice Guidelines. 2014 AHA/ACC/HRS guideline for the management of patients with atrial fibrillation: A report of the American College of Cardiology/ American Heart Association Task Force on Practice Guidelines and the Heart Rhythm Society. J Am Coll Cardiol 2014; 64: $\mathrm{e} 1-\mathrm{e} 76$.

6. Camm AJ, Lip GY, De Caterina R, Savelieva I, Atar D, Hohnloser SH, et al; ESC Committee for Practice Guidelines (CPG). 2012 focused update of the ESC Guidelines for the management of atrial fibrillation: An update of the 2010 ESC Guidelines for the management of atrial fibrillation: Developed with the special contribution of the European Heart Rhythm Association. Eur Heart J 2012; 33: 2719-2747.

7. Page RL. Clinical practice: Newly diagnosed atrial fibrillation. $N$ Engl J Med 2004; 351: 2408-2416.

8. Stewart S, Hart CL, Hole DJ, McMurray JJ. A population-based study of the long-term risks associated with atrial fibrillation: 20-year follow-up of the Renfrew/Paisley study. Am J Med 2002; 113: $359-364$

9. Lainscak M, Dagres N, Filippatos GS, Anker SD, Kremastinos DT. Atrial fibrillation in chronic non-cardiac disease: Where do we stand? Int J Cardiol 2008; 128: 311-315.

10. Sidney S, Sorel M, Quesenberry CP Jr, DeLuise C, Lanes S, Eisner MD. COPD and incident cardiovascular disease hospitalizations and mortality: Kaiser Permanente Medical Care Program. Chest 2005; 128: 2068-2075.

11. Mapel DW, Dedrick D, Davis K. Trends and cardiovascular co-morbidities of COPD patients in the Veterans Administration Medical System, 1991-1999. COPD 2005; 2: 35-41.

12. Ryynänen OP, Soini EJ, Lindqvist A, Kilpeläinen M, Laitinen $\mathrm{T}$. Bayesian predictors of very poor health related quality of life and mortality in patients with COPD. BMC Med Inform Decis Mak 2013; 13: 34 .

13. Steer J, Gibson J, Bourke SC. The DECAF Score: Predicting hospital mortality in exacerbations of chronic obstructive pulmonary disease. Thorax 2012; 67: 970-976.

14. Fuso L, Incalzi RA, Pistelli R, Muzzolon R, Valente S, Pagliari $\mathrm{G}$, et al. Predicting mortality of patients hospitalized for acutely exacerbated chronic obstructive pulmonary disease. Am J Med 1995; 98: 272-277.

15. Ogawa S, Aonuma K, Tse HF, Huang D, Huang JL, Kalman J, et al. The APHRS's 2013 statement on antithrombotic therapy of patients with nonvalvular atrial fibrillation. J Arrhythm 2013; 29: $190-200$.

16. Lip GY, Nieuwlaat R, Pisters R, Lane DA, Crijns HJ. Refining clinical risk stratification for predicting stroke and thromboembolism in atrial fibrillation using a novel risk factor-based approach: The euro heart survey on atrial fibrillation. Chest 2010; 137: 263-272.

17. Fuster V, Rydén LE, Cannom DS, Crijns HJ, Curtis AB, Ellenbogen KA, et al. 2011 ACCF/AHA/HRS focused updates incorporated into the ACC/AHA/ESC 2006 Guidelines for the management of patients with atrial fibrillation: A report of the American College of Cardiology Foundation/American Heart Association Task Force on Practice Guidelines developed in partnership with the European Society of Cardiology and in collaboration with the European Heart Rhythm Association and the Heart Rhythm Society. J Am Coll Cardiol 2011; 57: e101e198.

18. Melgaard L, Gorst-Rasmussen A, Lane DA, Rasmussen LH, Larsen TB, Lip GY. Assessment of the CHA2DS2-VASc score in predicting ischemic stroke, thromboembolism, and death in patients with heart failure with and without atrial fibrillation. JAMA 2015; 314: 1030-1038.

19. Saliba W, Rennert G. CHA2DS2-VASc score is directly associated with the risk of pulmonary embolism in patients with atrial fibrillation. Am J Med 2014; 127: 45-52.

20. Cetin M, Cakici M, Zencir C, Tasolar H, Baysal E, Balli M, et al. Prediction of coronary artery disease severity using CHADS2 and CHA2DS2-VASc scores and a newly defined CHA2DS2- 
VASc-HS score. Am J Cardiol 2014; 113: 950-956.

21. Paoletti Perini A, Bartolini S, Pieragnoli P, Ricciardi G, Perrotta L, Valleggi A, et al. CHADS2 and CHA2DS2-VASc scores to predict morbidity and mortality in heart failure patients candidates to cardiac resynchronization therapy. Europace 2014; 16: $71-80$.

22. National Health Research Institutes. National Health Insurance Research Database. http://nhird.nhri.org.tw/en/index.html (accessed April 14, 2015).

23. Hu WS, Lin CL. Association between cataract and risk of incident atrial fibrillation: A nationwide population-based retrospective cohort study. Mayo Clin Proc 2017; 92: 370-375.

24. Hsu CL, Wang TC, Shen TC, Huang YJ, Lin CL, Sung FC. Risk of depression in patients with chronic rhinosinusitis: A nationwide population-based retrospective cohort study. J Affect Disord 2016; 206: 294-299.

25. Chao TF, Liu CJ, Liao JN, Wang KL, Lin YJ, Chang SL, et al Use of oral anticoagulants for stroke prevention in patients with atrial fibrillation who have a history of intracranial hemorrhage. Circulation 2016; 133: 1540-1547.

26. Hu WS, Lin CL. CHA2DS2-VASc score in the prediction of ischemic bowel disease among patients with atrial fibrillation: Insights from a nationwide cohort. Int J Cardiol 2017; 235: $56-60$.

27. Harrell FE Jr, Lee KL, Mark DB. Multivariable prognostic models: Issues in developing models, evaluating assumptions and adequacy, and measuring and reducing errors. Stat Med 1996; 15: $361-387$.

28. Li J, Agarwal SK, Alonso A, Blecker S, Chamberlain AM,
London SJ, et al. Airflow obstruction, lung function, and incidence of atrial fibrillation: The Atherosclerosis Risk in Communities (ARIC) study. Circulation 2014; 129: 971-980.

29. Fuster V, Rydén LE, Cannom DS, Crijns HJ, Curtis AB, Ellenbogen KA, et al; Task Force on Practice Guidelines, American College of Cardiology/American Heart Association; Committee for Practice Guidelines, European Society of Cardiology; European Heart Rhythm Association; Heart Rhythm Society. ACC/AHA/ESC 2006 guidelines for the management of patients with atrial fibrillation - executive summary: A report of the American College of Cardiology/American Heart Association Task Force on Practice Guidelines and the European Society of Cardiology Committee for Practice Guidelines (Writing Committee to Revise the 2001 Guidelines for the Management of Patients with Atrial Fibrillation). Eur Heart J 2006; 27: 19792030.

30. Buch P, Friberg J, Scharling H, Lange P, Prescott E. Reduced lung function and risk of atrial fibrillation in the Copenhagen City Heart Study. Eur Respir J 2003; 21: 1012-1016.

31. Chamberlain AM, Agarwal SK, Folsom AR, Soliman EZ Chambless LE, Crow R, et al. A clinical risk score for atrial fibrillation in a biracial prospective cohort (from the Atherosclerosis Risk in Communities [ARIC] study). Am J Cardiol 2011; 107: $85-91$.

32. Schnabel RB, Sullivan LM, Levy D, Pencina MJ, Massaro JM, D'Agostino RB Sr, et al. Development of a risk score for atrial fibrillation (Framingham Heart Study): A community-based cohort study. Lancet 2009; 373: 739-745. 